\title{
Women with benign breast disease face higher cancer risk
}

task force also published an appeal in the German Medical Journal Deutsches Ärzteblatt (www.aerzteblatt.de/v4/archiv/ar tikel.asp?id=47 551).

The initiative is supported by an alliance of German medical organisations, including medical faculties, ethics committees, medical societies, the Science Council, and the German Medical Council. The German science ministry will fund the register, which is expected to be set up in the next three years. A final decision on where the register is to be based will be taken next year.

It is estimated that every year several thousand clinical trials are started in Germany, but most of them remain unknown to patients, doctors, and the scientific community until their results are published.

Only a few German studies are currently registered on the United Kingdom based International Standard Randomised Controlled Trial Number Register (www.controlled-trials.com) and the US ClinicalTrials.gov (www.clinicaltrials.gov)

Annette Tuffs Heidelberg

\section{Conference plans rebuilding of southern Sudan's health services}

Interim health ministers from Sudan's new government of national unity and from the semiautonomous government of southern Sudan met in London last week, with other health experts, to consider how to rebuild southern Sudan's shattered health services.

The new governments were established earlier this month as part of a peace agreement ending Africa's longest conflict.

The conference's organiser, Mohamed Baraka, a consultant ear, nose, and throat surgeon at Royal Lancaster Infirmary and formerly a professor at King Faisal University, Saudi Arabia, said, "The southern Sudan government must show strong political leadership to avert epidemics such as malaria, HIV/AIDs, and so on. Priorities are to be given to tropical and preventive medicine and especially the daunting challenges to eradicate typhoid, tetanus, whooping cough, tuberculosis, polio, and measles in children."

About a third of Sudan's total territory is in southern Sudan, which has a population of nine million. "This population is served by only 80 doctors and less than 600 nurses," Mr Baraka told the conference. However, millions of returning refugees need special attention, he said.

More details and the conference proceedings are available from the British and American Friends of Southern Sudan at baraka@btinternet.com

Peter Moszynski London

\section{US health system doesn't give value for money}

More is spent per person on health care in the United States than in any of the other 29 industrialised countries in the Organization for Economic Cooperation and Development (OECD). The reason is higher prices in the United States, not malpractice litigation and defensive medicine, says an annual study published in Health Affairs (2005;24:903-14).

The study also refutes the argument that high spending in the US means that healthcare capacity is high. It says that many other OECD countries have a higher number of doctors per population and their spending is much lower than that in the US

"It's the prices, stupid," the authors argued in a previous paper (Health Affairs 2003;22:89105). US prices are higher because "there's no single entity to negotiate with providers on prices," as there is in the United Kingdom and many other countries, said the lead author, Gerard Anderson, a professor at the Johns Hopkins Bloomberg School of Public Health, Baltimore.

In 2002 the amount spent per person on health care in the US was $\$ 5267$ (£3006; €4370) $53 \%$ more than any other country and $140 \%$ above the median (\$2193) for OECD countries. Janice Hopkins Tanne New York
Scott Gottlieb New York

Benign breast disease increases women's risk of developing breast cancer, especially if they have atypical lesions or a family history of breast cancer, a new study shows.

The researchers, led by Lynn Hartmann of the Division of Medical Oncology at the Mayo Clinic College of Medicine, Rochester, Minnesota, studied all women who received a diagnosis of benign breast disease at the Mayo Clinic between 1967 and 1991 to estimate the risk of their developing breast cancer and to find associations between the risk of cancer and various findings in benign disease (New England Jour nal of Medicine 2005;353:229-37 and 297-9).

To estimate relative risks the researchers compared the number of women who developed breast cancer with the number of cases expected on the basi of rates of breast cancer in the population covered by the Iowa surveillance, epidemiology, and end results registry.

The researchers followed a total of 9087 women for a median of 15 years, looking at family history of breast cancer and the histological grade of the women's benign disease, among other factors.

In the group 6061 of the women $(67 \%)$ had non-proliferative lesions, 2690 (30\%) had proliferative lesions without atypia and 336 (4\%) had atypical hyperplasia.

A total of 707 cases of breast cancer developed in the group. The relative risk of breast cancer for the group was 1.56 (95\% confidence interval 1.45 to 1.68$)$, and this increased risk persisted for at least 25 years after biopsy.

However, the relative risk associated with atypical hyperplasia was 4.24 (3.26 to 5.41), whereas that for proliferative changes without atypia was 1.88 (1.66 to 2.12) and that for non-proliferative lesions was 1.27 (1.15 to 1.41).

A major question concerns the possible interplay between atypia and a family history of breast cancer. An earlier study found that the risk of breast cancer in women with atypia and a family history was 11 times that in women with non-proliferative lesions and no family history (New
England Journal of Medicine 1985;312:146-51). However, two other major studies of benign breast disease found no significant interaction between atypia and family history (American Journal of Epidemiology 1988 128:467-77 and JAMA 1992;267: 941-4).

The authors of the current study found that the strength of the family history of breast cancer, available for only 4808 women $(53 \%)$ in the group, was a risk factor that was independent of histological findings.

Overall, the relative risk of developing breast cancer was 1.18 (1.01 to 1.37 ) in women with no known family history, 1.43 (1.15 to 1.75 ) in women with a weak family history, and 1.93 (1.58 to 2.32) in those with a strong family history.

In an accompanying editorial Joann Elmore, of the Department of Medicine at the University Of Washington School of Medicine in Seattle, and Gerd Gigerenzer, of the Max Planck Institute for Human Development in Berlin, write that the link between family history and histological findings was weakened by the fact that family history was available for only $53 \%$ of the women that the researchers followed.

However, they write that overall "these data solidify what has long been known about the risk of breast cancer among women with benign breast disease and help stratify women with a benign lesion into high-risk and low-risk groups.'

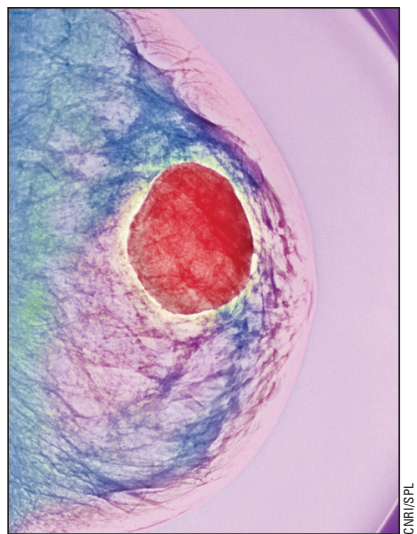

Women with benign breast disease were 1.56 times more likely to develop breast cancer than women in the general population 